\title{
Synthesis and olefin homo- and copolymerization behavior of new vanadium complexes bearing [OSSO]-type ligands
}

\author{
Marzena Białek $^{1}$ - Julia Fryga ${ }^{1}$ - Grzegorz Spaleniak ${ }^{1} \cdot$ \\ Marta Żołnowska ${ }^{1}$
}

Received: 8 May 2017/ Accepted: 13 July 2017/Published online: 21 July 2017

(C) The Author(s) 2017. This article is an open access publication

\begin{abstract}
Novel vanadium complexes bearing [OSSO]-type ligands having two phenolato units linked through the $-\mathrm{CH}_{2} \mathrm{~S}\left(\mathrm{CH}_{2}\right)_{4} \mathrm{SCH}_{2}-(\mathbf{1 V})$ or $-\mathrm{CH}_{2} \mathrm{~S}\left(\mathrm{CH}_{2}\right)_{2}$ $\mathrm{SCH}_{2}-(\mathbf{2 V})$ bridge are synthesized with good yields by reacting a deprotonated ligand with $\mathrm{VCl}_{4}$. They are then used in ethylene (co)polymerization after activation with $\mathrm{EtAlCl}_{2}$ and $\mathrm{Et}_{2} \mathrm{AlCl}$. In the presence of $\mathrm{EtAlCl}_{2}$, both complexes promote ethylene polymerization with very high activities, over $4 \times 10^{7} \mathrm{~g} /(\mathrm{mol} \mathrm{h})$, leading to PEs with high molecular weight and narrow molecular weight distribution. The prepared complexes exhibit lower activity for ethylene/1-octene copolymerization. It is also revealed that the catalyst based on the $-\mathrm{CH}_{2} \mathrm{~S}\left(\mathrm{CH}_{2}\right)_{4} \mathrm{SCH}_{2}-$ bridged complex shows both higher activity and higher comonomer incorporation ability than the catalyst based on the $-\mathrm{CH}_{2} \mathrm{~S}\left(\mathrm{CH}_{2}\right)_{2} \mathrm{SCH}_{2}-$ bridged complex. Upon activation with $\mathrm{Al}(i \mathrm{Bu})_{3} / \mathrm{Ph}_{3} \mathrm{CB}\left(\mathrm{C}_{6} \mathrm{~F}_{5}\right)_{4}$, complex $2 \mathrm{~V}$ produces stereo- and regioirregular poly(1-octene), while $\mathbf{1 V}$ gives the isotactically enriched product.
\end{abstract}

Keywords Vanadium complex · [OSSO]-ligand · Ziegler-Natta polymerization · Polyolefins · Copolymers

\section{Introduction}

Developing new olefin polymerization catalysts on the basis of transition metal complexes with various ligands makes one of the most interesting areas of chemical research in recent years. Amongst such complexes, those of transition metals of group 4 with [ON] or [ONNO] ligands offer the most interesting properties [1-4]. For example, catalysts based on phenoxy-imine complexes may be not only more

Marzena Białek

marzena.bialek@uni.opole.pl

1 Faculty of Chemistry, Opole University, Oleska 48, 45-052 Opole, Poland 
active than the metallocene catalysts, but they make it possible to produce a variety of polyolefinic materials, inclusive of ultra-high-molecular-weight PEs, welldefined multimodal PEs, selective vinyl- and Al-terminated PEs, isotactic and syndiotactic PPs, as well as stereo- and regioirregular high-molecular weight poly(1-olefin)s [1]. Group 4 transition metal complexes which incorporate tetradentate [OSSO]-type bis(phenolate) ligands have also been quite extensively studied in homo- and copolymerization of olefins as well as in polymerization of styrene and its derivatives, and in olefin-styrene copolymerization [5-18]. The titanium complex of the tetradentate [OSSO]-type diphenolate ligand with the 1,4dithiabutanediyl-bridge yielded isotactic PS at very high activity. Polystyrene materials with the same microstructures were produced by $\mathrm{Zr}$ and $\mathrm{Hf}$ complexes bearing the identical ligand but with low yields [8]. On the other hand, titanium complexes with the longer and more flexible 1,5-dithiapentanediyl bridge promote syndiospecific styrene polymerization with relatively low activity [11]. The metal center is also important for ethylene polymerization promoted by $[\mathrm{OSSO}] \mathrm{MCl}_{2} /$ MAO ( $\mathrm{M}=\mathrm{Ti}, \mathrm{Zr})$ catalysts [9]. The zirconium complex produced exclusively oligomers with even numbers of carbon atoms while its titanium analogue gave branched polymers $[9,12]$. Another zirconium complex as well as the hafnium one, having a ligand bearing trans-1,2-cyclooctanediylbis(thio) core, were highly active in 1-hexene polymerization providing highly isotactic poly(1-hexene) $[15,16]$. It was also shown that the regioselectivity during 1-hexene oligomerization switched when the titanium metal center was replaced with its heavier homolog ( $\mathrm{Zr}, \mathrm{Hf})$ [10]. The dichloro $\{1,4$-dithiabutanediyl-2,2'-bis(4,6-di-tert-butylphenoxy) $\}$ titanium complex activated by MAO catalyzed olefin/styrene copolymerization and produced relatively high molecular weight ethylene/styrene copolymers with high styrene contents [6] and multiblock copolymers which contained long isotactic styrene sequences interrupted by short isotactic propylene strings [7]. That catalyst was also active in the copolymerization of conjugated dienes with ethylene and provided prevailingly alternating copolymers [13], in the copolymerization of ethylene with 4-methyl-1,3-pentadiene [17], and it catalyzed the homopolymerization of conjugated dienes as well [18]. Enantiomerically pure titanium complexes which contained trans-1,2-cyclohexanediyl-linked [OSSO]-type bis(phenolate) ligand were found to produce low-molecular-weight homochiral isotactic oligostyrenes which showed optical activity [14]. There are also known group 4 metal complexes with $o$-carborane-bridged [OSSO]-type tetradentate ligands with high activity towards ethylene homo- and copolymerization [19]. In contrast to group 4 elements, the group 5 complexes bearing [OSSO]-type bis(phenolate) ligands are rare [20, 21]. The oxovanadium(V) complex in conjunction with MAO showed high activity in ethylene polymerization but did not catalyze the propylene and styrene polymerization [20], and the tantalum(V) complex activated with $\mathrm{Al}(i \mathrm{Bu})_{3} / \mathrm{Ph}_{3} \mathrm{CB}\left(\mathrm{C}_{6} \mathrm{~F}_{5}\right)_{4}$ gave isotactic poly(1-hexene) with narrow dispersity [21].

The design and synthesis of new vanadium complexes which bear other chelating ligands attract however more and more interest recently [22-30]. It results from the interesting catalytic properties of this type of catalysts. Classical vanadium catalysts are able to produce high molecular weight polymers with narrow molecular weight distributions, high molecular weight amorphous ethylene/propylene copolymers, 
syndiotactic propylene [22, 31, 32]. The problem of using vanadium catalysts is their rapid deactivation associated with reduction of catalytically active vanadium species to inactive vanadium(II) species, especially at higher temperatures $[22,23,31,32]$. Adding chelating ligands to the vanadium compound can help in stabilizing the vanadium species at a high oxidation state [31]. Furthermore, the catalytic properties of the vanadium complex can be modified by the structure of the ligand used.

Within this study, new vanadium(IV) complexes were synthesized with the [OSSO]-type ligands, wherein the phenolate rings were bridged by the structure $\mathrm{CH}_{2} \mathrm{~S}\left(\mathrm{CH}_{2}\right)_{n} \mathrm{SCH}_{2}-(\mathrm{n}=2$ or 4$)$, and their catalytic performance was verified in the ethylene and 1-octene polymerization processes, as well as in the copolymerization of those monomers. Moreover, the obtained products were analyzed in detail.

\section{Experimental part}

All manipulations of air-sensitive and/or moisture-sensitive compounds were performed under an inert atmosphere, using standard Schlenk techniques and a glove box.

\section{Materials}

Argon (grade 5.0, Air Liquide), $\mathrm{Et}_{2} \mathrm{AlCl}$ (1.0 M, Sigma-Aldrich), EtAlCl ${ }_{2}$ (1.0 M, Sigma-Aldrich), $\mathrm{Al}(i \mathrm{Bu})_{3}$ (1.0 M, Aldrich), $\mathrm{Ph}_{3} \mathrm{CB}\left(\mathrm{C}_{6} \mathrm{~F}_{5}\right)_{4}$ (min. 97\%, Strem Chemicals), $\mathrm{NaH}\left(60 \%\right.$, Sigma-Aldrich), $\mathrm{VCl}_{4}$ (Sigma-Aldrich), 1,4-butanedithiol (98\%, Sigma-Aldrich), 1,2-ethanedithiol ( $>90 \%$, Sigma-Aldrich) were used as received. THF and hexane were refluxed over sodium/benzophenone and then distilled, and toluene was refluxed over sodium and distilled. 1-Octene (98\%, Sigma-Aldrich) and dichloromethane were dried under argon over 4A molecular sieves. Ethylene (grade 3.5, Linde Gas) and nitrogen (Messer) were used after having been passed through a column with sodium metal supported on $\mathrm{Al}_{2} \mathrm{O}_{3}$.

\section{General methods}

The infrared spectra were recorded with the Nicole Nexus 2002 FT-IR spectrometer with a constant spectral resolution $\mathrm{R}=2 \mathrm{~cm}^{-1}$ and were taken over the spectral range 4000-400 $\mathrm{cm}^{-1}$. Each sample was scanned 20 times. The samples of ligands and complexes were prepared under the inert atmosphere as a suspension in Nujol. Samples of (co)polymers were tested as a disk with $\mathrm{KBr}$. The comonomer incorporation was determined using the modified IR method and the equation: 1-Oct $(\mathrm{mol} \%)=1.7211\left(\mathrm{~A}_{\mathrm{CH} 3} / \mathrm{A}_{\mathrm{CH} 2}\right)_{\mathrm{s}}^{2}+4.0123\left(\mathrm{~A}_{\mathrm{CH} 3} / \mathrm{A}_{\mathrm{CH} 2}\right)_{\mathrm{s}}-0.0029$ [33]. The ${ }^{1} \mathrm{H}$ NMR and ${ }^{13} \mathrm{C}$ NMR spectra were recorded with the $400 \mathrm{MHz}$ Ultrashield Bruker spectrometer. The ethylene/1-octene copolymers were analyzed in 1,2-dichlorobenzene- $\mathrm{d}_{4}$ at $120{ }^{\circ} \mathrm{C}$. The samples of poly(1-octene)s and ligands were dissolved in $\mathrm{CDCl}_{3}$ and their analyses were performed at room temperature. The melting temperatures $\left(\mathrm{T}_{\mathrm{m}}\right)$ and crystallinity $(\chi)$ of polymers were determined by differential 
scanning calorimetry with a 2010 DSC calorimeter from TA Instruments at the heating rate $10{ }^{\circ} \mathrm{C} / \mathrm{min}$. Gel permeation chromatography was used for the determination of polymer molecular weights and molecular weight distributions. Analyses were performed using an Alliance 135 GPCV 2000 apparatus equipped with HT 3 and HT $6 \mathrm{E}$ columns at $135{ }^{\circ} \mathrm{C}$ using 1,2,4-trichlorobenzene $(1.0 \mathrm{~mL} /$ min) as a solvent. The calibration curve was obtained with a narrow dispersity polystyrene standards having molecular weight range of 1000-3.7 $\times 10^{6} \mathrm{~g} / \mathrm{mol}$.

\section{Synthesis of the ligand precursor $\mathrm{H}_{2} \mathrm{~L}^{1}$}

A two-neck round bottom flask was charged sequentially with THF (30 mL), 2,4-ditert-butyl-6-hydroxymethylphenol $\quad(2.00 \mathrm{~g}, \quad 8.46 \mathrm{mmol}), \quad$ 1,4-butanedithiol (0.16 mL, $4.23 \mathrm{mmol})$ and $\mathrm{H}_{2} \mathrm{SO}_{4}(1 \mathrm{~mL})$. The obtained clear, light yellow solution was stirred for $24 \mathrm{~h}$ and then $100 \mathrm{~mL}$ of water was added. After the evaporation of THF, the product was extracted by methylene chloride. The extract was dried over anhydrous $\mathrm{MgSO}_{4}$ and then evaporated. The dry residue $(2.68 \mathrm{~g})$ was crystallized from $\mathrm{MeOH} / \mathrm{H}_{2} \mathrm{O}$. A precipitate was collected by filtration, and then dried in vacuo. $1.63 \mathrm{~g}(69 \%)$ of a white solid was obtained.

\section{Synthesis of the ligand precursor $\mathrm{H}_{2} \mathrm{~L}^{2}$}

Ligand precursor $\mathrm{H}_{2} \mathrm{~L}^{2}$ was synthesized according to the method described for $\mathrm{H}_{2} \mathrm{~L}^{1}$. Synthesis was conducted with $2.00 \mathrm{~g}(8.46 \mathrm{mmol})$ of 2,4-di-tert-butyl-6hydroxymethylphenol and $0.38 \mathrm{~mL}(4.23 \mathrm{mmol})$ of 1,2-ethanedithiol. $1.75 \mathrm{~g}(77 \%)$ of a white solid was obtained.

\section{Synthesis of complex 1V}

To a stirred colorless solution of ligand precursor $\mathrm{H}_{2} \mathrm{~L}^{1}(0.50 \mathrm{~g}, 0.91 \mathrm{mmol})$ in dry THF (50 mL), $0.073 \mathrm{~g}$ of $\mathrm{NaH}(60 \%$ in oil, $1.82 \mathrm{mmol})$ was added. After $2 \mathrm{~h}$, to the reaction mixture solution of $\mathrm{VCl}_{4}(0.94 \mathrm{mmol})$ in toluene $(5 \mathrm{~mL})$ was added dropwise and it was stirred for next $4 \mathrm{~h}$. The solution turned dark green and a precipitate was formed. The precipitate was filtered and dried in vacuum to an oily residue. The resulting oil was dissolved in dry methylene chloride/hexane mixture $(10 \mathrm{~mL} / 10 \mathrm{~mL})$ and the solution was put into a freezer overnight. A precipitate was collected by filtration and dried under reduced pressure to give $0.43 \mathrm{~g}(69 \%)$ of a dark blue-green solid.

\section{Synthesis of complex $2 \mathrm{~V}$}

Vanadium complex $\mathbf{2 V}$ was synthesized according to the method described for $\mathbf{1 V}$. Reaction was carried out in THF $(50 \mathrm{~mL})$ using $0.70 \mathrm{~g}(1.32 \mathrm{mmol})$ of $\mathrm{H}_{2} \mathrm{~L}^{2}$, $0.106 \mathrm{~g}(2.64 \mathrm{mmol}) \mathrm{NaH}$ and $0.14 \mathrm{~mL}(1.32 \mathrm{mmol}) \mathrm{VCl}_{4} .2 \mathrm{~V}$ was obtained as a dark blue-green powder in $77 \%(0.66 \mathrm{~g})$ yield. 


\section{Ethylene homo- and copolymerization procedure}

Ethylene (co)polymerization was carried out in a Büchi glass autoclave equipped with the magnetic stirrer and heating-cooling jacket. The required amounts of solvent (150 mL of hexane), 1-octene (in case of copolymerization) and the activator were introduced into the reactor following this order. Then, after the prescribed temperature was reached, the toluene solution of complex was added. (Co)polymerization was started after introducing ethylene and the pressure was kept constant at 5 bar throughout the reaction time. Termination was performed by venting the reactor and transferring the obtained mixture to a dilute solution of hydrochloric acid in methanol. The polymer was filtered, washed a few times with methanol and dried initially in air and then in vacuum oven.

\section{1-Octene polymerization procedure}

1-Octene polymerization was carried out in a two-neck $100 \mathrm{~mL}$ flask equipped with a magnetic stirrer. First the monomer, and then $\mathrm{Al}(i \mathrm{Bu})_{3}$, the vanadium complex and last $\mathrm{Ph}_{3} \mathrm{CB}\left(\mathrm{C}_{6} \mathrm{~F}_{5}\right)_{4}$ were introduced into the flask. The mixture was stirred for the prescribed time. The reaction was terminated by adding the acidified methanol. The obtained polymer was washed with methanol and dried in air and then in vacuum oven at $45^{\circ} \mathrm{C}$.

\section{Result and discussion}

\section{Synthesis of ligands and complexes}

By reacting 2,4-di-tert-butyl-6-hydroxymethylphenol with 1,4-butanedithiol and with 1,2-ethanedithiol (Scheme 1), two [OSSO]-type ligands were synthesized with different numbers of $\mathrm{CH}_{2}$ groups in the bridge which linked the donor sulfur atoms. The yield of synthesis reached $69 \%$ for $\mathrm{H}_{2} \mathrm{~L}^{1}$ and $77 \%$ for $\mathrm{H}_{2} \mathrm{~L}^{2}$. The ${ }^{1} \mathrm{H} \mathrm{NMR}$

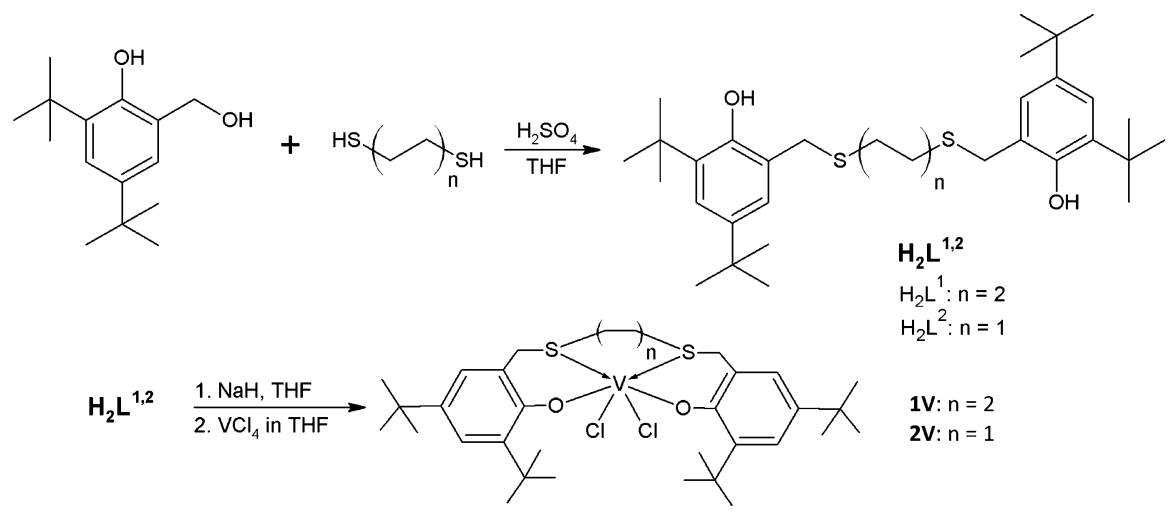

Scheme 1 Synthesis of ligands and their vanadium complexes 
spectra of those ligands (Fig. 1) reveal signals for tert-butyl groups (1.28 and $1.41 \mathrm{ppm}$ as well as 1.26 and $1.41 \mathrm{ppm}$ in the $\mathrm{H}_{2} \mathrm{~L}^{1}$ and $\mathrm{H}_{2} \mathrm{~L}^{2}$ spectra, respectively), the proton signal of the groups $\mathrm{ArCH}_{2} \mathrm{~S}$ (3.78 and $3.75 \mathrm{ppm}$ in the $\mathrm{H}_{2} \mathrm{~L}^{1}$ and $\mathrm{H}_{2} \mathrm{~L}^{2}$ spectra), two doublets at 6.90 and $7.26 \mathrm{ppm}$ as well as 6.89 and $7.26 \mathrm{ppm}$ in the $\mathrm{H}_{2} \mathrm{~L}^{1}$ and $\mathrm{H}_{2} \mathrm{~L}^{2}$ spectra, respectively, which come from aromatic protons, and the proton signal of hydroxyl groups, which was observed in the spectra of those ligands at 6.72 and $6.50 \mathrm{ppm}$. Moreover, two signals can be seen in the spectrum for the ligand $\mathrm{H}_{2} \mathrm{~L}^{1}$, at $1.57 \mathrm{ppm}$ and at $2.34 \mathrm{ppm}$ for the protons of the $\mathrm{CH}_{2}$ groups in the butylene bridge, while the spectrum of the ligand with the ethylene bridge shows a signal at $2.56 \mathrm{ppm}$, which can be ascribed to the ethylene bridge $\mathrm{CH}_{2}$ protons.
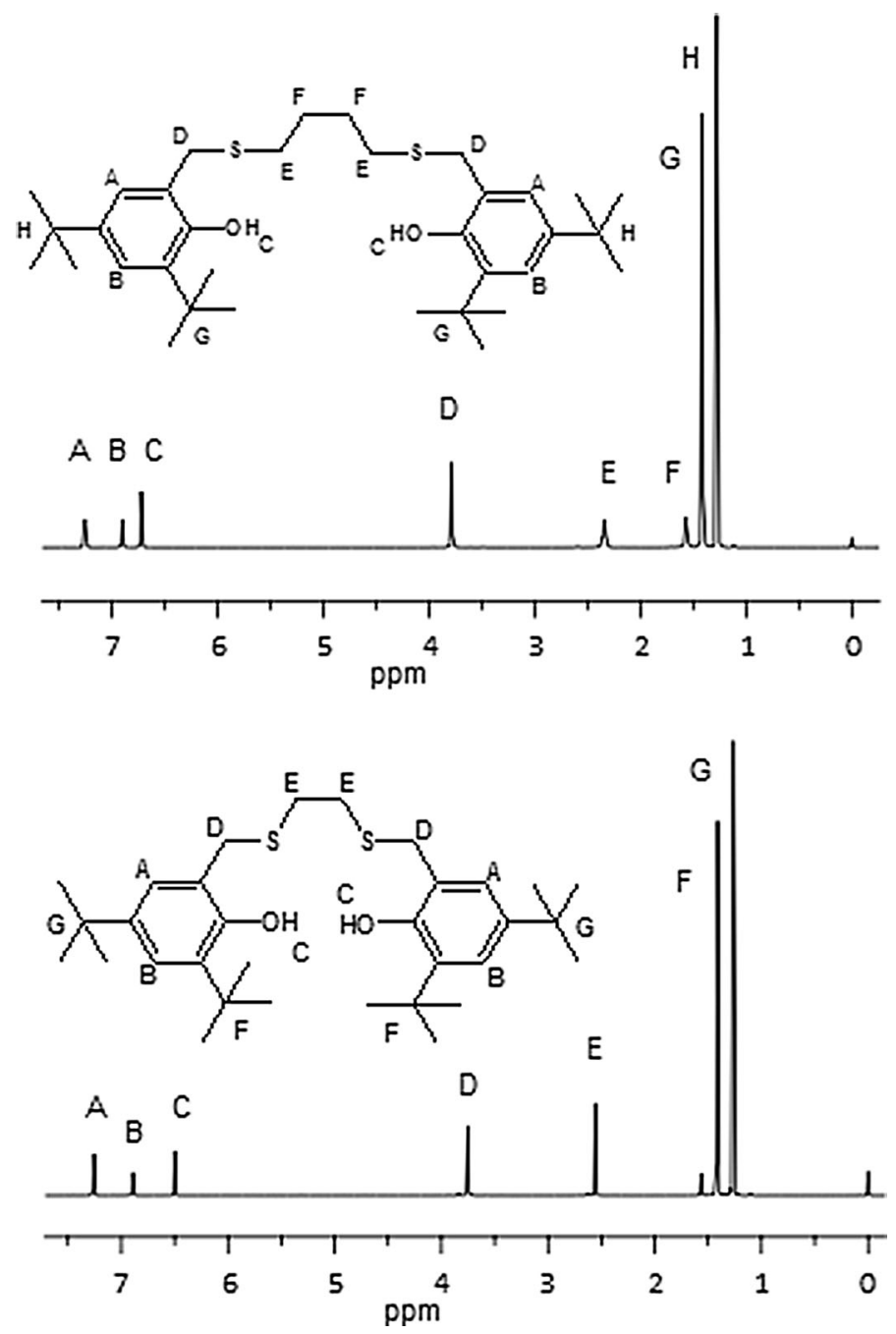

Fig. $1{ }^{1} \mathrm{H}$ NMR spectra of $\mathrm{H}_{2} \mathrm{~L}^{1}$ and $\mathrm{H}_{2} \mathrm{~L}^{2}$ 
The prepared tetradentate ligand precursors were deprotonated with $\mathrm{NaH}$ and then they were reacted with 1.0 equivalent of $\mathrm{VCl}_{4}$ in toluene. A general synthetic route for the complexes is shown in Scheme 1. After workup, the complexes were isolated as dark blue-green powders at moderate yields: $0.43 \mathrm{~g}$ of $\mathbf{1 V}$ and $0.66 \mathrm{~g}$ of $2 V$. Both complexes, and ligand precursors for comparison, were characterized by FTIR spectroscopy. The obtained spectra are presented in Fig. 2. As can be seen, the spectra of the complexes are different from those of the appropriate ligands, which confirms the reaction to have occurred. The bands present in the spectra of ligands at about $3262 \mathrm{~cm}^{-1}\left(\mathrm{H}_{2} \mathrm{~L}^{1}\right)$ and $3345 \mathrm{~cm}^{-1}\left(\mathrm{H}_{2} \mathrm{~L}^{2}\right)$ due to the disappearance of the stretching $\mathrm{O}-\mathrm{H}$ frequencies in the spectra of the complexes. Ligands exhibit the bands at $1601,1593 \mathrm{~cm}^{-1}\left(\mathrm{H}_{2} \mathrm{~L}^{1}\right)$ and $1603,1591 \mathrm{~cm}^{-1}\left(\mathrm{H}_{2} \mathrm{~L}^{2}\right)$ as a result of $v(\mathrm{C}=\mathrm{C})$ vibration. These bands appear at $1612,1593 \mathrm{~cm}^{-1}(\mathbf{1 V})$ and $1594 \mathrm{~cm}^{-1}$ $(\mathbf{2 V})$ in the spectra of vanadium complexes. The band observed at around $1200 \mathrm{~cm}^{-1}$ and $1196 \mathrm{~cm}^{-1}$ in the spectra of ligands is attributed to the phenolic $v(\mathrm{C}-\mathrm{O})$ vibration and in the spectra of complexes it is seen at 1226 and $1225 \mathrm{~cm}^{-1}$. Such changes confirm the formation of the $\mathrm{V}-\mathrm{O}$ bonds. It is also confirmed by a new band, which appeared at around $480 \mathrm{~cm}^{-1}$, which can represent the $v(\mathrm{~V}-\mathrm{O})$ mode [34]. Moreover, the changed location can be observed for the band which is specific for the $v(C-S)$ and which can be observed at 1221 and $1238 \mathrm{~cm}^{-1}$ for ligands and at 1243 and $1246 \mathrm{~cm}^{-1}$ for complexes [35]. The bands due to $v(\mathrm{~V}-\mathrm{Cl})$ were not observed because they are usually present in the far infrared region below $400 \mathrm{~cm}^{-1}$ [36].

\section{Ethylene homo- and copolymerization}

The ability of the vanadium complexes to polymerize ethylene was investigated after their activation by the $\mathrm{EtAlCl}_{2}$ or $\mathrm{Et}_{2} \mathrm{AlCl}$. Polymerization experiments were conducted in hexane using $0.5 \mu \mathrm{mol}$ of the vanadium complex. The reaction temperature was set up at $30{ }^{\circ} \mathrm{C}$ since the vanadium compounds are known to readily undergo reduction to lower oxidation states which are inactive in polymerization $[22,23]$. To overcome this problem, the reactivating agents are often used, even at low temperatures [23]. Few vanadium catalysts are known so far
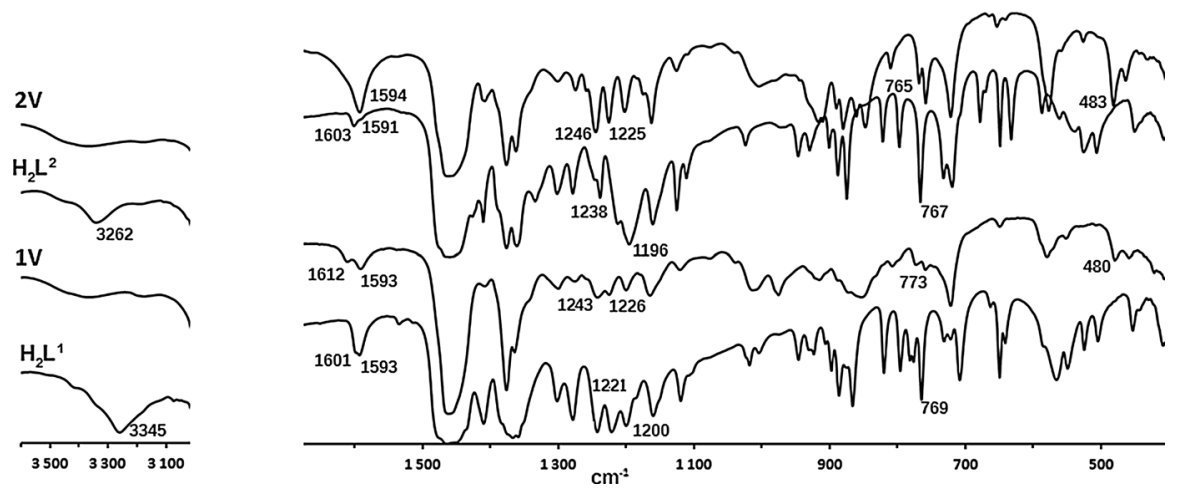

Fig. 2 FTIR spectra of complexes $\mathbf{1 V}$ and $2 \mathrm{~V}$ as well as corresponding ligand precursors $\mathrm{H}_{2} \mathrm{~L}^{1}$ and $\mathrm{H}_{2} \mathrm{~L}^{2}$ 
to display high thermal stability, for example (arylimido)vanadium(V) complexes with tridentate Schiff base ligands [37]. Table 1 summarizes the polymerization results and reaction conditions. Both vanadium complexes were most active when activated with $\mathrm{EtAlCl}_{2}$ (entries 1 and 8). Their activities were very high, over $40,000 \mathrm{~kg} /(\mathrm{mol} \mathrm{h})$. Besides, the activities of the studied vanadium complexes are much higher than those observed in ethylene polymerization for titanium, hafnium and zirconium complexes which contain [OSSO] ligands of different structure $[12,19]$, and for the vanadium(V) complex which contains a trans-1,2-dithiacyclohexane-bridged bis(phenolato) ligand activated with MAO [20]. After the complex amount was reduced to $0.05 \mu \mathrm{mol}$, the activity of the catalysts was lowered, which may result from easier reduction of vanadium to inactive oxidation states at a very high $\mathrm{Al}: \mathrm{V}$ molar ratio amounting to 60,000:1, with a higher loss of activity observed for the complex $\mathbf{2 V}$. In general, the catalysts which are based on the complex having the $-\mathrm{CH}_{2} \mathrm{~S}\left(\mathrm{CH}_{2}\right)_{4} \mathrm{SCH}_{2}-$ bridge (1V) show a higher activity than those based on the complex with the $-\mathrm{CH}_{2} \mathrm{~S}\left(\mathrm{CH}_{2}\right)_{2} \mathrm{SCH}_{2}-$ bridge (2V). The opposite effect of the bridge length, e.g. lower activity for a complex bearing a longer bridge, was observed earlier for bis(phenolate) titanium complexes with 1,4dithiabutanediyl and 1,5-dithiapentanediyl bridges [12], which may result both from different metal centres in a complex and from different ligand structures. As can be seen from Table 1, all the produced polyethylenes possess high molecular weight and high melting temperature in the range $137.3-139.9^{\circ} \mathrm{C}$. In addition, the molecular weight distribution for these polymers is very narrow (in the range of 1.4-1.7), which can suggest that the investigated catalysts are single-site in nature.

Polymerization tests were also conducted in the presence of methylaluminoxane however very low catalytic activities were obtained (e.g. the activity of 1V/MAO was equal to $292 \mathrm{~kg} /(\mathrm{mol} \mathrm{h})$ ).

Having in mind the importance of branched polyethylenes and the lack of information about the catalytic properties of [OSSO]-type complexes (with the exception of $\mathrm{Ti}$ and $\mathrm{Zr}$ complexes with the [OSSO]-carborane ligand [19]) in the copolymerization of ethylene with 1-olefins, the ethylene/1-octene copolymerization was investigated. The copolymerization ability of both complexes was estimated after activation by $\mathrm{EtAlCl}_{2}$ and $\mathrm{Et}_{2} \mathrm{AlCl}$ under the same polymerization conditions: $30 \mathrm{~min}, 30{ }^{\circ} \mathrm{C}, 5$ bar of ethylene and $3 \mathrm{mmol}$ of activator. 10,5 and $2 \mathrm{~mL}$ of 1-octene was used in the copolymerization, which corresponds to the ratio of the molar concentrations of 1-octene/ethylene in the feed equal $0.53,0.27$ and 0.11 (ethylene concentration under the reaction conditions was used as reported in [38]). The results are collected in Table 1 . The catalytic activity of all the systems was lower for copolymerization than that for homopolymerization of ethylene. This negative "comonomer effect" is frequently observed in ethylene/1-olefin copolymerization with different catalytic systems [39]. The incorporation of 1-olefin into the copolymer at the same 1-olefin concentration depends on the catalytic system type: $1 \mathrm{~V} / \mathrm{Et}_{2} \mathrm{AlCl}$ was found to give the product with about twice higher content of comonomer than $2 \mathrm{~V} / \mathrm{Et}_{2} \mathrm{AlCl}$ (Table 1 , run 7 vs. 14). In addition, the increase of ratio of the molar concentrations of the comonomers, from 0.27 to 0.53 , resulted in higher 1-octene incorporation into the copolymer from 2.8 to $3.9 \%$ mol (run 6 and 7). 





The obtained copolymers had different thermal and molecular properties than their corresponding polyethylenes. First of all, their melting points and crystallinity were lowered. $\mathrm{T}_{\mathrm{m}}$ and crystallinity of $\mathrm{PE}$ produced by $1 \mathrm{~V} / \mathrm{Et}_{2} \mathrm{AlCl}$ were equal to $139.1{ }^{\circ} \mathrm{C}$ and $60.8 \%$, and they decreased to $119.8{ }^{\circ} \mathrm{C}, 41.7 \%$ and $113.2{ }^{\circ} \mathrm{C}, 34.8 \%$ after 5 and $10 \mathrm{~mL}$ of 1 -octene was added to the polymerization feed, respectively (Table 1, Fig. 3). Moreover, a clear widening of the melting peaks of copolymers can be observed in DSC curves in relation to melting peaks of homopolymers, which is indicative for heterogeneity of the chemical compositions of those copolymers. Even higher heterogeneity is shown by the copolymers obtained with the use of $2 \mathrm{~V} / \mathrm{Et}_{2} \mathrm{AlCl}$. The DSC thermogram of the copolymer 14 (Fig. 3) reveals the presence of two macromolecular fractions with highly different melting points, i.e. with different comonomer incorporation levels. It should be emphasized that the obtained copolymers are not homogeneous from the viewpoint of their chemical compositions, yet they offer very narrow molecular-weight distributions $\left(\mathrm{M}_{\mathrm{w}} / \mathrm{M}_{\mathrm{n}}=1.4\right)$, just alike ethylene homopolymers. Fig. 4 presents DSC curves for copolymers obtained with the use of both vanadium complexes activated with $\mathrm{EtAlCl}_{2}$. As can be seen, those copolymers offer much lower $\mathrm{T}_{\mathrm{m}}$ values than the copolymers obtained with the use of $\mathrm{Et}_{2} \mathrm{AlCl}$ at the same comonomer concentration in the reaction medium, thus at a higher incorporation level of the comonomer. Adding the comonomer to the reaction medium and increasing its concentration also resulted in lower molecular weights of copolymers, which can be accounted for by the involvement of 1-octene in the polymer chain termination reaction (Fig. 5).

The microstructure of the copolymers was analyzed by ${ }^{13} \mathrm{C}$ NMR spectroscopy (Fig. 6). The assignment of the peaks to specific carbon atom was made based on $[40,41]$. The spectrum of poly(ethylene-co-1-octene) produced by $\mathbf{1 V} / \mathrm{Et}_{2} \mathrm{AlCl}$ (run 6) exhibits signals at $14.05(1 \mathrm{~s}+1 \mathrm{~B} 6), 22.89(2 \mathrm{~s}+2 \mathrm{~B} 6), 27.35(\beta \delta+5 \mathrm{~B} 6), 30.02$ $(\delta \delta+4 \mathrm{~B} 6), 30.50(\gamma \delta), 32.22(3 \mathrm{~B} 6), 34.61(\alpha \delta+6 \mathrm{~B} 6)$ and $38.23 \mathrm{ppm}(\mathrm{CH})$, indicating that the copolymer contains isolated 1-octene units. In the spectrum of copolymer 9, which was synthesized with $2 \mathrm{~V} / \mathrm{EtAlCl}_{2}$, additional peaks at 31.86 and

Fig. 3 DSC thermograms (co)polymers produced by $1 \mathrm{~V} /$ $\mathrm{Et}_{2} \mathrm{AlCl}$ and $2 \mathbf{V} / \mathrm{Et}_{2} \mathrm{AlCl}$

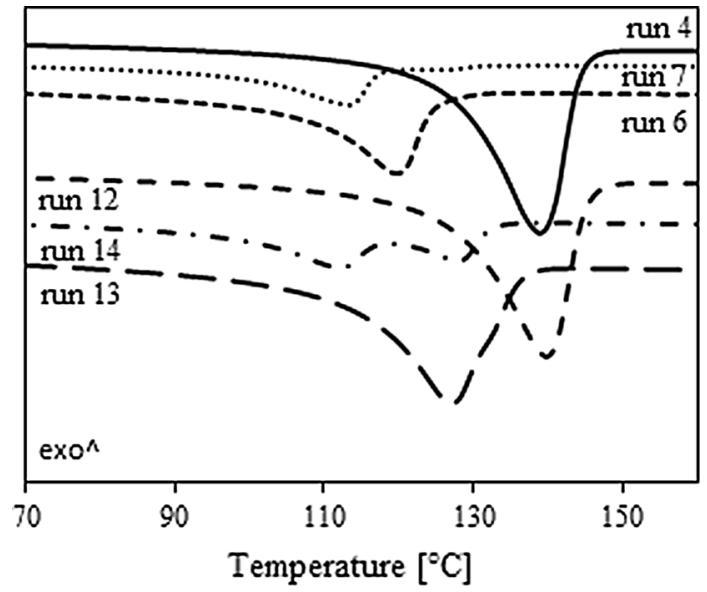


Fig. 4 DSC thermograms (co)polymers produced by $\mathbf{1 V /}$ $\mathrm{EtAlCl}_{2}$ and $\mathbf{2} \mathrm{V} / \mathrm{EtAlCl}_{2}$

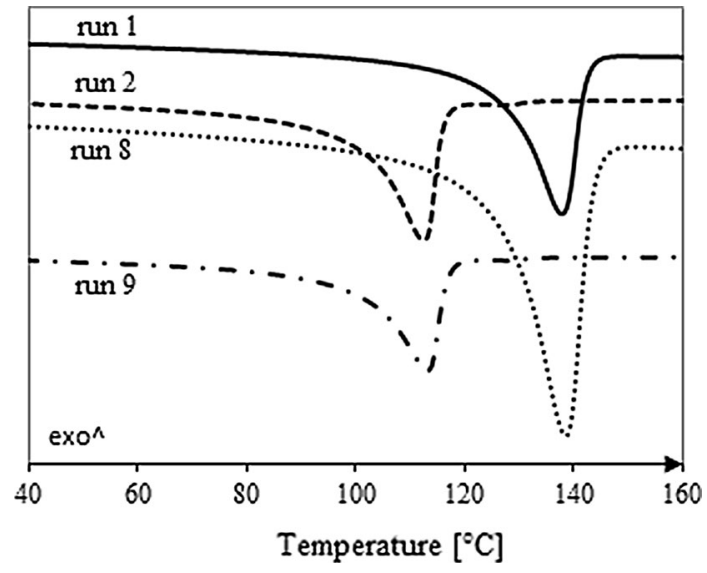

at about $41 \mathrm{ppm}$ can be seen due to the presence of $\alpha \alpha$ and $\gamma \gamma$ carbon atoms, which reveals the presence of OEEO-type and blocky sequences of 1-octene units. Moreover, additional signals are present in the spectrum which may be indicative for the presence of the 1-octene homopolymer. Hence, a fraction soluble in $\mathrm{CHCl}_{3}$ was separated from the copolymer and its share amounted to $38 \%$. Its analysis by the ${ }^{13} \mathrm{C}$ NMR method (Fig. 6c) confirmed the presence of poly(1-olefin) with branched structure according to [42].

\section{Polymerization of 1-octene}

Both complexes in conjunction with $\mathrm{Al}(i \mathrm{Bu})_{3} / \mathrm{Ph}_{3} \mathrm{CB}\left(\mathrm{C}_{6} \mathrm{~F}_{5}\right)_{4}$ were tested in 1-octene homopolymerization. As can be seen in Table 2, their activity in that reaction was very low. 1-Octene conversion was below 2\% and increasing the reaction time to $6 \mathrm{~h}$ (run

Fig. 5 GPC curves for ethylene/1-octene copolymers synthesized with $1 \mathrm{~V} / \mathrm{Et}_{2} \mathrm{AlCl}$

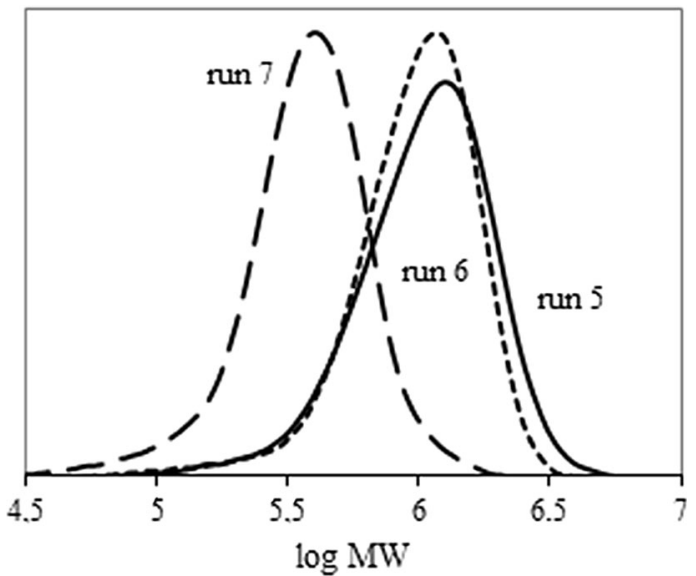




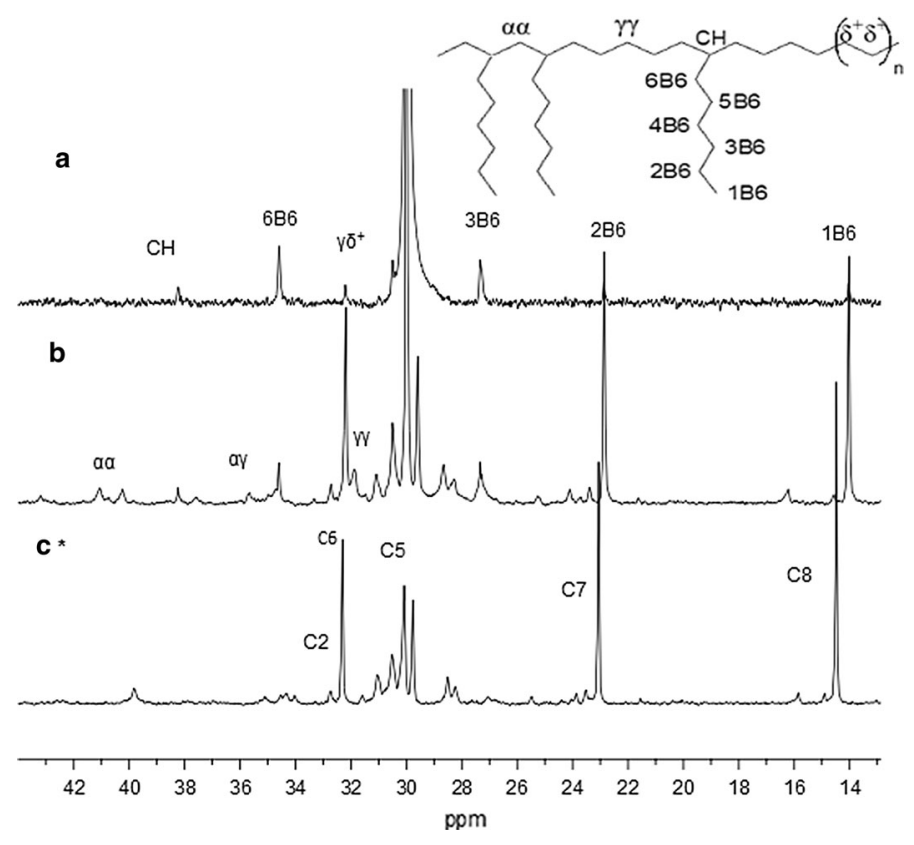

Fig. $6{ }^{13} \mathrm{C}$ NMR spectrum of ethylene/1-octene copolymer synthesized with $1 \mathrm{~V} / \mathrm{Et}_{2} \mathrm{AlCl}$, run 6 (a) and $\mathbf{2} / \mathrm{EtAlCl}_{2}$, run 9 (b) as well as polyolefin extracted from copolymer 9 (c)

Table 2 Results of 1-octene polymerization catalyzed by vanadium complexes activated by $\mathrm{Al}(i \mathrm{Bu})_{3} /$ $\mathrm{Ph}_{3} \mathrm{CB}\left(\mathrm{C}_{6} \mathrm{~F}_{5}\right)_{4}$

\begin{tabular}{lllcl}
\hline Run & Complex & $\begin{array}{l}\text { Time } \\
(\mathrm{min})\end{array}$ & $\begin{array}{l}\text { Yield } \\
(\mathrm{mg})\end{array}$ & $\begin{array}{l}\text { Conversion } \\
(\%)\end{array}$ \\
\hline 15 & $\mathbf{1 V}$ & 120 & 45 & 0.8 \\
16 & $\mathbf{2 V}$ & 120 & 93 & 1.6 \\
17 & $\mathbf{2 V}$ & 360 & 232 & 4.1 \\
\hline
\end{tabular}

Conditions: $0.03 \mathrm{mmol}$ of complex, $0.025 \mathrm{mmol}$ of $\mathrm{Ph}_{3} \mathrm{CB}\left(\mathrm{C}_{6} \mathrm{~F}_{5}\right)_{4}, 0.45 \mathrm{mmol}$ of $\mathrm{Al}(i \mathrm{Bu})_{3}$, RT $\left(23{ }^{\circ} \mathrm{C}\right)$, $8 \mathrm{~mL}$ of 1-octene

17) raised the comonomer conversion to $4.1 \%$. The activity of the previously studied vanadium(V) complex, [OSSO]VO(OPr), was even lower [21]. In general, the vanadium complexes reported for 1-olefin homopolymerization are very rare [43]. The microstructure of the produced polymers was characterized by ${ }^{13} \mathrm{C}$ NMR spectroscopy. The resonances in the spectra (Fig. 7) were assigned based on earlier reports $[44,45]$. The very broad signal around $35 \mathrm{ppm}$ in the spectrum in Fig. 7b, which is assigned to the $\mathrm{C} 3$ carbon, is indicative for the atactic nature of poly(1-octene) produced by $2 \mathbf{V}$. This spectrum, apart from signals of carbon C1-C8, exhibits the additional peak at $28.5 \mathrm{ppm}$ which originates from enchained regioerrors [44]. In the ${ }^{1} \mathrm{H}$ NMR spectrum of that polymer, in its olefinic region, there are signals at 5.4 and 


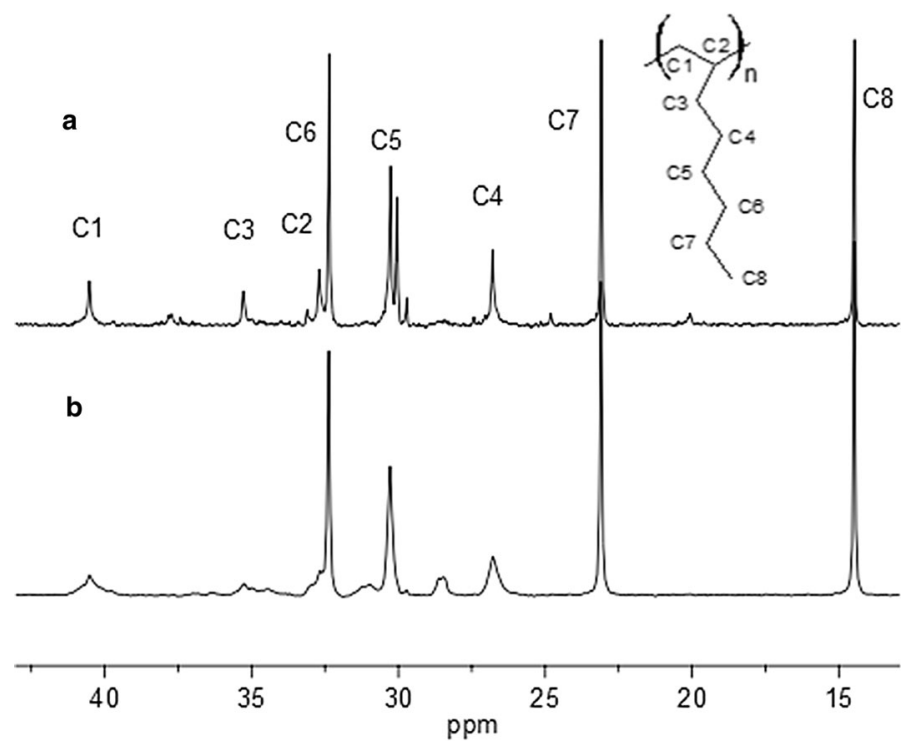

Fig. $7{ }^{13} \mathrm{C}$ NMR spectra of poly(1-octene)s obtained in run 17 (b) and in run 15 (a)

$4.7 \mathrm{ppm}$ due to vinylene and vinylidene end groups. The presence of those groups results from the monomolecular or bimolecular (with the monomer involved) $\beta-\mathrm{H}$ elimination, which was preceded by a growth of macromolecule via the 2,1 -insertion and 1,2-insertion mechanisms, respectively. Poly(1-octene) synthesised with 1V (Fig. 7a) is also atactic, with the share of isotactic pentad equal to $28.2 \%$.

\section{Conclusions}

Tetradentate [OSSO]-type ligand precursors were easily synthesized in the one pot procedure by reacting 2,4-di-tert-butyl-6-hydroxymethylphenol with 1,4-butanedithiol or 1,2-ethanedithiol. Using the obtained compounds, new vanadium complexes were prepared and utilized in ethylene and 1-octene homopolymerization, and in ethylene/1-octene copolymerization. In conjunction with EtAlCl${ }_{2}$, they turned out highly active in ethylene homopolymerization, over $4 \times 10^{7} \mathrm{~g} /(\mathrm{mol} \mathrm{h})$, while its activity was lower after activation with $\mathrm{Et}_{2} \mathrm{AlCl}$, up to $1.5 \times 10^{6} \mathrm{~g} /$ (mol h). The produced PEs had high molecular weights and very narrow dispersity. Besides, the vanadium catalysts catalyzed ethylene/1-octene copolymerization with low activity and yielded the products with medium comonomer incorporation only. Their catalytic properties were also dependent on the complex structure. The catalyst based on the $-\mathrm{CH}_{2} \mathrm{~S}\left(\mathrm{CH}_{2}\right)_{4} \mathrm{SCH}_{2}$ - bridged complex (1V) showed both a higher activity and a higher comonomer incorporation ability than the complex $\mathbf{2} \mathbf{V}$ based on the $-\mathrm{CH}_{2} \mathrm{~S}\left(\mathrm{CH}_{2}\right)_{2} \mathrm{SCH}_{2}-$ bridge. Upon activation with $\mathrm{Al}(i \mathrm{Bu})_{3} / \mathrm{Ph}_{3-}$ $\mathrm{CB}\left(\mathrm{C}_{6} \mathrm{~F}_{5}\right)_{4}$, the complex $2 \mathrm{~V}$ produced stereo- and regioirregular poly(1-octene), while $1 \mathrm{~V}$ gave the isotactically enriched product. 
Acknowledgements This work was supported by the research grant No. N N209 140840 from the National Science Center (NCN, Poland).

Open Access This article is distributed under the terms of the Creative Commons Attribution 4.0 International License (http://creativecommons.org/licenses/by/4.0/), which permits unrestricted use, distribution, and reproduction in any medium, provided you give appropriate credit to the original author(s) and the source, provide a link to the Creative Commons license, and indicate if changes were made.

\section{References}

1. Matsugi T, Fujita T (2008) Chem Soc Rev 37:1264-1277

2. Makio H, Terao H, Iwashita A, Fujita T (2011) Chem Rev 111:2363-2449

3. Busico V, Cipullo R, Friederichs N, Ronca S, Talarico G, Togrou M, Wang B (2004) Macromolecules 37:8201-8203

4. Tshuva EY, Groysman S, Goldberg I, Kol M, Goldschmidt Z (2002) Organometallics 21:662-670

5. Nakata N, Toda T, Ishii A (2011) Polym Chem 2:1597-1610

6. Capacchione C, Proto A, Ebeling H, Mülhaupt R, Okuda J (2006) J Polym Sci Part A 44(6):1908-1913

7. Capacchione C, De Carlo F, Zannoni C, Okuda J, Proto A (2004) Macromolecules 37:8918-8922

8. Capacchione C, Proto A, Ebeling H, Mülhaupt R, Möller K, Spaniol TP, Okuda J (2003) J Am Chem Soc 125:4964-4965

9. Mella M, Izzo L, Capacchione C (2011) ACS Catal 1:1460-1468

10. Lian B, Beckerle K, Spaniol TP, Okuda J (2007) Angew Chem Int Ed 46:8507-8510

11. Capacchione C, Manivannan R, Barone M, Beckerle K, Centore R, Oliva L, Proto A (2005) Organometallics 24:2971-2982

12. Capacchione C, Proto A, Okuda J (2004) J Polym Sci Part A 42:2815-2822

13. Capacchione C, Avagliano A, Proto A (2008) Macromolecules 41:4573-4575

14. Meppelder G-JM, Beckerle K, Manivannan R, Lian B, Raabe G, Spaniol TP, Okuda J (2008) Chem Asian J 3:1312-1323

15. Ishii A, Toda T, Nakata N, Matsuo T (2009) J Am Chem Soc 131:13566-13567

16. Nakata N, Toda T, Matsuo T, Ishii A (2013) Macromolecules 46:6758-6764

17. Proto A, Avagliano A, Saviello D, Capacchione C (2009) Macromolecules 42:6981-6985

18. Milione S, Cuomo C, Capacchione C, Zannoni C, Grassi A, Proto A (2007) Macromolecules 40:5638-5643

19. Hu P, Wang J-Q, Wang F, Jin G-X (2011) Chem Eur J 17:8576-8583

20. Meppelder G-JM, Halbach TS, Spaniol TP, Mülhaupt R, Okuda J (2009) J Organomet Chem 694:1235-1237

21. Toda T, Nakata N, Matsuo T, Ishii A (2013) ACS Catal 3:1764-1767

22. Nomura K, Zhang S (2011) Chem Rev 111:2342-2362

23. Wu J-Q, Li Y-S (2011) Coord Chem Rev 255:2303-2314

24. Zhang S-W, Lu L-P, Long Y-Y, Li Y-S (2013) J Polym Sci Part A 51:5298-5306

25. Do Prado NT, Ribeiro RR, Casagrande OL Jr (2016) Appl Organometal Chem. doi:10.1002/aoc.3678

26. Redshaw C, Walton MJ, Elsegood MRJ, Priora TJ, Michiued K (2015) RSC Adv 5:89783-89796

27. Wang W, Nomura K (2006) Adv Synth Catal 348:743-750

28. Tang L-M, Wu J-Q, Duan Y-Q, Pan L, Li Y-G, Li Y-S (2008) J Polym Sci Part A 46:2038-2048

29. Wu J-Q, Mu J-S, Zhang S-W, Li Y-S (2010) J Polym Sci A 48:1122-1132

30. Homden D, Redshaw C, Warford L, Hughes DL, Wright JA, Dale SH, Elsegood MRJ (2009) Dalton Trans 41:8900-8910

31. Hagen H, Boersma J, van Koten G (2002) Chem Soc Rev 31:357-364

32. Gambarotta S (2003) Coord Chem Rev 237:229-243

33. Sudoł M, Czaja K, Białek M (2000) Polimery 45:405-410

34. Sharma N, Thakur MM, Kumar V, Chaudhary SC (2008) Indian J Chem 47A:685-689

35. Si G, Zhang L, Han B, Duan Z, Li B, Dong J, Li X, Liu B (2015) Polym Chem 6:6372-6377 
36. El-Dissouky A, Shehata AK, El-Mahdey G (1997) Polyhedron 16:1247-1253

37. Lu L-P, Wang J-B, Liu J-Y, Li Y-S (2014) J Polym Sci Part A 52:2633-2642

38. Sivalingam G, Natarajan V, Sarma KR, Parasuveera U (2008) Ind Eng Chem Res 47:8940-8946

39. Chien JCW, Nozaki T (1993) J Polym Sci Part A 31:227-237

40. Qiu XH, Redwine D, Gobbi G, Nuamthanom A, Rinaldi PL (2007) Macromolecules 40:6879-6884

41. Galland GB, Mauler RS, de Menezes SC, Quijada R (1995) Polym Bull 34:599-604

42. Obuah C, Munyaneza A, Guzei IA, Darkwa J (2014) Dalton Trans 43:8940-8950

43. Lorber C, Wolff F, Choukroun R, Vendier L (2005) Eur J Inorg Chem 14:2850-2859

44. Saito J, Suzuki Y, Makio H, Tanaka H, Onda M, Fujita T (2006) Macromolecules 39:4023-4031

45. Asakura T, Demura M, Nishiyama Y (1991) Macromolecules 24:2334-2340 